\title{
Anti-Helicobacter pylori, anti-inflammatory and antioxidant evaluation of crude extracts from Amomum krervanh fruits
}

\author{
Bhanuz Dechayont $^{\mathrm{a}, *}$, Pathompong Phuaklee ${ }^{\mathrm{a}}$, Jitpisute Chunthorng-Orn ${ }^{\mathrm{a}}$, Saovapak Poomirat ${ }^{\mathrm{a}}$, \\ Onmanee Prajuabjinda ${ }^{\mathrm{a}}$, Ratha-korn Vilaichone ${ }^{\mathrm{b}}$, Arunporn Itharat ${ }^{\mathrm{a}, \mathrm{c}}$ \\ a Department of Applied Thai Traditional Medicine, Faculty of Medicine, Thammasat University, \\ Pathum Thani, Thailand \\ b Gastroenterology Unit, Department of Medicine, Thammasat University, Pathum Thani, Thailand \\ c Center of Excellence in Applied Thai Traditional Medicine Research, Thammasat University, \\ Pathum Thani, Thailand
}

*Corresponding author, e-mail: Nuzz@hotmail.com

Received 2 Apr 2018

Accepted 5 Apr 2019

\begin{abstract}
The aim of the present study was to determine the antibacterial properties against Helicobacter pylori and the anti-inflammatory and antioxidant activities of crude $A$. krervanh extracts. The minimum inhibitory concentrations (MICs) of ethanolic and aqueous extracts were measured against standard strain $H$. pylori standard (ATCC 43504) and six clinical isolates by disc diffusion and agar dilution. Anti-inflammatory activities were evaluated by measuring the inhibition of nitric oxide (NO) production in LPS-activated RAW 264.7 macrophages using the Griess assay and the ELISA measurement of proinflammatory cytokines, tumour necrosis factor $\alpha$ (TNF- $\alpha$ ), and interleukin 6 (IL-6). Their cytotoxic activities against macrophages were determined by the MTT assay. ABTS and DPPH scavenging assays measured the antioxidant activities. Only the ethanolic extract showed antibacterial activity with mean inhibition zones of 9.0-19.3 mm for a corresponding MIC of $250 \mu \mathrm{g} / \mathrm{ml}$; the clarithromycin MICs ranged from $0.5-1 \mu \mathrm{g} / \mathrm{ml}$. This extract also inhibited production of NO (mean $\mathrm{IC}_{50} 98.99 \pm 0.39 \mu \mathrm{g} / \mathrm{ml}$ ) and IL-6 (mean IC s0 $18.68 \pm 2.16 \mu \mathrm{g} / \mathrm{ml}$ ) and exhibited moderate antioxidant activity using $\mathrm{DPPH}$ and $\mathrm{ABTS}$ scavenging assays: mean $\mathrm{IC}_{50} \mathrm{~s} 95.92 \pm 1.26$ and $90.35 \pm 2.25 \mu \mathrm{g} / \mathrm{ml}$, respectively. Thus ethanolic extract showed a greater spectrum of activity that could be exploited further as adjunct treatments of $H$. pylori related gastrointestinal disease.
\end{abstract}

KEYWORDS: anti-Helicobacter pylori, Amomum krervanh, nitric oxide, tumor necrosis factor $\alpha$, interleukin 6

\section{INTRODUCTION}

Functional dyspepsia (FD) which is the most common of dyspepsia is a disorder of the upper gastrointestinal tract of the stomach and duodenum and has several underlying pathophysiological mechanisms ${ }^{1}$. A syndrome consists of epigastric pain, burning, fullness, discomfort, early satiety, nausea, vomiting, and belching that affects quality of life ${ }^{2}$. Furthermore, from previous report in Thailand, 60\% of patients diagnosed with FD were found to be infected with Helicobacter pylori ${ }^{3}$. The infection of $H$. pylori may have reduction in ghrelin secretion that may reduce gastric mobility of patients with $H$. pylori associated diseases ${ }^{2}$. Furthermore, $H$. pylori is the most important cause of gastric inflammation which develop to gastritis, peptic ulcers and gastric cancer ${ }^{4}$. Success rates for treating dyspepsia due to an identified pathology is to reduce or eliminate the symptoms and thus to improve the conditions of the patient. There are at least four pathophysiologic mechanisms, for example the delayed gastric emptying, impaired post-prandial fundus relaxation, hypersensitivity to gastric distension, and acid-related or acid hypersensitivity, recommended therapy includes acid suppressive ther$a^{2}{ }^{3}$. However, many patients with FD often seek out complementary and alternative therapies, such as herbal medicines, because of the limited effects of the conventional therapies.

In Thailand, patients often seek traditional remedies for common symptoms and hold beliefs related to wind and fire elements in their body. One commonly used remedy for dyspepsia is cardamom ${ }^{5}$.

Cardamom, Amomum krervanh Pierre (Zingiberaceae), is a herbaceous plant whose fruit and 
seeds are fragrant ${ }^{6}$. The fruit is used commonly in tea in India and has been used historically to relieve indigestion and flatulence. Furthermore, cardamom has been found to possess antioxidant ${ }^{7}$ and antimalarial properties ${ }^{8}$. Cardamom fruit contains several compounds such as 1,8-cineol (eucalyptol), terpinine, borneol, camphor and limonene. The major compound of the essential oil is 1,8 cineole (eucalytol) ${ }^{9,10}$ which shows a potential antiinflammatory activity ${ }^{11}$.

The body of literature on these potentially useful properties is very limited. We, therefore, conducted a study to assess the antibacterial, antiinflammatory and antioxidant properties of $A$. $k r$ ervanh fruit.

\section{MATERIALS AND METHODS}

\section{Plant materials}

A. krervanh plants were purchased from a herbal shop in January 2017 in Nakhon Pathom province, Thailand.

\section{Chemicals}

All the chemicals and reagents used were of analytical grade. 2,2-diphenyl-1-picrylhydrazyl, 2,2'-azino-bis(3-ethylbenzothiazoline-6sulphonic acid) diammonium salt, 6-hydroxy2,5,7,8-tetramethylchroman-2-carboxylic acid (Trolox), $\mathrm{AlCl}_{3}$, potassium acetate, potassium persulphate, phosphoric acid, dimethyl sulphoxide, lipopolysaccharide from E. coli O55:B5 (LPS), $\mathrm{N}$-(1-Naphthyl) ethylenediamine dihydrochloride, sulfanilamide, 3-(4,5-dimethyl-2-thiazolyl)-2,5diphenyl-2H-tetrazolium bromide or thiazolyl blue tetrazolium bromide (MTT) and trypan blue dye were purchased from Sigma-Aldrich, USA. Folin-Ciocalteu's reagent and $\mathrm{Na}_{2} \mathrm{CO}_{3}$ were purchased from Fluka, USA, and Merck, Germany, respectively. Mouse TNF- $\alpha$ and mouse IL- 6 ELISA kits were purchased from Immuno Tools, Germany. $\mathrm{HCl}$ and isopropanol were purchased from RCI Labscan, Thailand. Dulbecco's modified Eagle medium (DMEM), butylated hydroxytoluene (BHT), phosphate-buffered saline, brain heart infusion and anaeropack microaero were purchased from Gibco BRL, USA, Fluka, Biochrom, Germany, Difco, USA, and Mitsubishi Gas Chemical America, USA, respectively.

\section{Ethanolic extract}

A total of $50 \mathrm{~g}$ of dried fruit of A. krervanh was exhaustively extracted with aqueous $95 \%$ ethanol (v/v) by maceration at room temperature for 3 days. The extract was obtained after filtration and concentration of the material under reduced pressure using a rotary evaporator. Then the extract was dried using vacuum dryers.

\section{Water extract}

A total of $50 \mathrm{~g}$ of dried fruits was boiled with deionized water for $15 \mathrm{~min}$, then the aqueous extract was filtered using Whatman paper no 1. Finally, lyophilizer was used to dry extract.

\section{Stock solution}

A stock solution of the water extract was made with sterile distilled water to a concentration of $100 \mathrm{mg} / \mathrm{ml}$; the ethanolic extract also was made with dimethylsulphoxide (DMSO) to a concentration of $500 \mathrm{mg} / \mathrm{ml}$. Both were used in the disc diffusion and agar dilution tests. Stock solutions of $10 \mathrm{mg} / \mathrm{ml}$ (water extract) and $50 \mathrm{mg} / \mathrm{ml}$ (ethanolic extract) were also made up to perform the antiinflammatory assays.

\section{Bacterial strains used and culture conditions}

H. pylori reference strain (ATCC 43504) was obtained from the American Type Culture Collection and six clinical isolates were obtained from human stomach biopsy specimens (kindly provided by Dr Ratha-korn Vilaichone, Faculty of Medicine, Thammasat University, Thailand). Strains were cultured on Columbia agar supplemented with $5 \%$ sheep's blood (RPD, Thailand) and incubated at $37^{\circ} \mathrm{C}$ under microaerobic conditions $\left(\mathrm{N}_{2}, 85 \% ; \mathrm{O}_{2}\right.$, $5 \% ; \mathrm{CO}_{2}, 10 \%$ ) using a gas generating kit. H. pylori was subcultured every 3 days in an anaerobic jar.

\section{Testing for anti-H. pylori activity by disc diffusion method}

H. pylori was inoculated and incubated at $37^{\circ} \mathrm{C}$ under microaerobic conditions for 3 days, then adjusted equivalently to approximately $0.5 \mathrm{McF}$ arland standard. Filter paper discs (6 $\mathrm{mm}$ in diameter) were impregnated of the extract $(1 \mathrm{mg} /$ disc $)$. Airdried discs were placed onto the Columbia $5 \%$ sheep blood agar. Clarithromycin (10 $\mu \mathrm{g} /$ disc) was used as the positive control. The plates were incubated as previously described for 3 days. The zone of inhibition was calculated by measuring the diameter of the inhibition zone three times and taking the mean value ${ }^{12,13}$. 


\section{Testing for anti-H. pylori activity by agar dilution}

The minimum inhibitory concentration (MIC) ${ }^{14,15}$ was determined by the agar dilution method following the Clinical and Laboratory Standards Institute (CLSI) guidelines. The extracts were serially diluted 2-fold in Columbia agar containing 5\% sheep's blood, then transferred separately into Petri dishes. The final concentrations of the extracts in the culture medium ranged from 2000 to $31.25 \mu \mathrm{g} / \mathrm{ml}$. A 72-h bacterial colony of $H$. pylori was harvested and suspended in brain heart infusion. Bacterial suspensions were prepared to approximately 2.0 of the McFarland standard. Bacterial suspension ( $3 \mu 1$ per spot) was replicated on each plate followed by incubating at $37^{\circ} \mathrm{C}$ for $72 \mathrm{~h}$ under microaerobic conditions. The MIC was defined as the lowest concentration of extract at which no visible growth was observed. All tests were conducted in triplicate, in addition to growth control with and without DMSO.

\section{Anti-inflammatory activity}

To evaluate anti-inflammatory activity, inhibition of proinflammatory cytokine (NO, TNF- $\alpha$, and IL6) was studied in RAW 264.7 macrophage cells obtained from Faculty of Medicine, Thammasat University, Thailand.

\section{Measurement of NO production in macrophage}

RAW 264.7 cells were seeded in 96-well plates $\left(1 \times 10^{5}\right.$ cells per well) and incubated at $37^{\circ} \mathrm{C}$ in a $5 \% \mathrm{CO}_{2}$ incubator for overnight. Then the cells were replaced and replenished with $5 \mathrm{ng} / \mathrm{ml}$ of lipopolysaccharide (LPS) and the extracts at various concentrations were incubated at $37^{\circ} \mathrm{C}$ in a humidified atmosphere containing $5 \% \mathrm{CO}_{2}$. At the end of $48 \mathrm{~h}, 100 \mu \mathrm{l}$ of supernatant was mixed with $100 \mu l$ of the Griess reaction, incubated for $10 \mathrm{~min}$ at room temperature, and then measured absorbance at $570 \mathrm{~nm}^{16}$.

\section{LPS-induced cytokine production assay}

Production of mouse TNF- $\alpha$ and IL- 6 was measured using an enzyme-linked immunosorbent assay (ELISA) ${ }^{17,18}$ according to manufacturer's instructions. Briefly, RAW 264.7 cells were seeded in 96well plates $\left(1 \times 10^{5}\right.$ cells per well $)$ and incubated at $37^{\circ} \mathrm{C}$ in a $5 \% \mathrm{CO}_{2}$ incubator for $24 \mathrm{~h} .5 \mathrm{ng} / \mathrm{ml}$ of LPS and various concentrations of the extracts were added to the wells. After $48 \mathrm{~h}$, the culture supernatants were analysed. Briefly, a 96-well microtitre plate was pre-coated overnight with capture antibody. After blocking and several washes, samples were incubated with working standards for $1 \mathrm{~h}$. After further washing, detection-antibody was added to each well and incubated for $2 \mathrm{~h}$. After washing, poly-HRP-streptavidin was added and incubated for $30 \mathrm{~min}$; then the substrate solution was added and incubated for $1 \mathrm{~h}$ with $3,5,3,5^{\prime}$ tetramethylbenzidine (TMB) solution. Finally, $50 \mu \mathrm{l}$ of stop solution was added to each well and the absorbance was read within 30 min using a microplate reader at $450 \mathrm{~nm}$ and $630 \mathrm{~nm}$.

\section{Cytotoxicity MTT assay}

Briefly, RAW264.7 cells were incubated with MTT ${ }^{16}$ ( $5 \mathrm{mg} / \mathrm{ml}$ in phosphate-buffered saline, $\mathrm{pH}$ 7.4) for $4 \mathrm{~h}$. Formed MTT formazan was solubilized with $100 \mu \mathrm{l}$ of isopropanol containing $0.04 \mathrm{M} \mathrm{HCl}$. Cell growth was determined by reading the absorbance at $570 \mathrm{~nm}$. The extract concentrations which produce more than $70 \%$ of cell survival were calculated.

\section{DPPH radical scavenging activity}

Antioxidant activity was determined using the DPPH assay, according to the modified method of Yamasaki et $\mathrm{al}^{19,20}$. The extracts were prepared with different concentrations $(1-100 \mu \mathrm{g} / \mathrm{ml})$. Then DPPH solution was freshly prepared in absolute ethanol and adjusted to a final DPPH concentration of $100 \mu \mathrm{M}$. DPPH was kept in a light protected bottle. The mixture was left to stand for $30 \mathrm{~min}$ in the dark at room temperature. The decrease in absorbance due to DPPH was measured at $520 \mathrm{~nm}$ using a microplate reader and the antioxidant activity measured in $\mu \mathrm{g} / \mathrm{ml}$; the $\mathrm{IC}_{50}$ was defined as the concentration of inhibitor necessary to reduce $50 \%$ of the $\mathrm{DPPH}^{\circ}$ radical.

\section{ABTS radical scavenging assay}

ABTS $^{+}$solution was produced by mixing $7 \mathrm{mM}$ ABTS stock solution in distilled water with $2.45 \mathrm{mM}$ potassium persulphate. The mixture was allowed to stand in the dark at room temperature for $12-16 \mathrm{~h}$ and the $\mathrm{ABTS}^{++}$solution was diluted with distilled water to an absorbance of $0.68-0.72$ at $734 \mathrm{~nm}$ before use. The reaction was carried out for $6 \mathrm{~min}$, and then the absorbance was measured at $734 \mathrm{~nm}$ using a microplate reader. The scavenging activity of the extracts against $\mathrm{ABTS}^{++}$was measured in $\mu \mathrm{g} / \mathrm{ml}$; the $\mathrm{IC}_{50}$ was defined as the concentration of inhibitor necessary to reduce $50 \%$ of the ABTS $^{+}$ radical $^{21}$. 


\section{Determination of total phenolic content}

The extract and gallic acid standard were transferred to 96-well microplates. Then FolinCiocalteu's reagent and 7.5\% (v/w) $\mathrm{Na}_{2} \mathrm{CO}_{3}$ solution were added and mixed. The plate was incubated for $30 \mathrm{~min}$ at room temperature $25^{\circ} \mathrm{C}$. Absorbance at $765 \mathrm{~nm}$ was measured using a microplate reader. A calibration curve of gallic acid was constructed to determine the amount of total phenolic content, which was expressed as $\mathrm{mg}$ of gallic acid equivalent (GAE) per $1 \mathrm{~g}$ of dry extract ${ }^{22}$.

\section{Determination of total flavonoid content}

The extract or quercetin standard was mixed in methanol, $10 \%(\mathrm{w} / \mathrm{v}) \mathrm{AlCl}_{3}, 1 \mathrm{M}$ potassium acetate and distilled water. The mixture was incubated at room temperature for $30 \mathrm{~min}$. Absorbance was determined at $415 \mathrm{~nm}$. A calibration curve of quercetin was constructed to determine the amount of total flavonoid content, which was expressed as $\mathrm{mg}$ of quercetin equivalent per $1 \mathrm{~g}$ of dry extract ${ }^{22}$.

\section{Statistical analysis}

All the experiments were conducted in triplicate. Results are expressed as a mean \pm standard error of the mean.

\section{RESULTS}

The extract yields of $A$. krervanh prepared by maceration and boiling methods are presented in Table 1. The higher yield was obtained from the water extract $(6.98 \%)$.

The results of the anti- $H$. pylori effect of A. krervanh extracts are shown in Table 2. The ethanolic extract exhibited an inhibition zone of $12 \mathrm{~mm}$ against the standard strain with an MIC of $250 \mu \mathrm{g} / \mathrm{ml}$. It also showed strong anti-H. pylori against the six clinical isolates with inhibition zones of 9.0-19.3 mm and minimum inhibitory concentrations (MICs) of $250 \mu \mathrm{g} / \mathrm{ml}$. All of these zones of inhibition were less than those of clarithromycin and had higher MICs. There was no growth inhibition with the water based extract with corresponding MICs of $2000-4000 \mu \mathrm{g} / \mathrm{ml}$.

As seen in Table 3, the ethanolic extract displayed dose-dependent and higher NO and IL-6 inhibition compared to the water extract and had $\mathrm{IC}_{50} \mathrm{~S}$ of $98.99 \pm 0.39$ and $18.68 \pm 2.16 \mu \mathrm{g} / \mathrm{ml}$, respectively. These results are supported by the cell viability of more than $80 \%$ by MTT assay.

The DPPH and ABTS determined antioxidant activities of the A. krervanh fruit extracts are summa- rized in Table 1. The water extract scavenged DPPH radicals with an $\mathrm{IC}_{50}$ value of $51.08 \pm 0.50 \mu \mathrm{g} / \mathrm{ml}$ that was lower compared to the ethanolic extract. In contrast, the ethanolic extract possessed the highest antioxidant activity by the ABTS assay with a mean $\mathrm{IC}_{50}$ of $90.35 \pm 2.25 \mu \mathrm{g} / \mathrm{ml}$.

The phenolic content was greater in ethanolic extract than in water extract which was found to be $36.95 \pm 0.65,31.52 \pm 1.85 \mathrm{mg} \mathrm{GAE} / \mathrm{g}$, respectively. Additionally, the amount of flavonoids was related to total phenolic content.

\section{DISCUSSION}

Extraction is an important step in the phytochemical process for discovering bioactive constituents of plant material. The study has shown that the water and ethanolic components of the cardamom plant possessed antioxidant activity but that the ethanolic component had appreciable antibacterial and antiinflammatory properties.

In this study, the anti-H. pylori activities of the water and ethanolic extracts were evaluated by disc diffusion method and by agar dilution. Although the CLSI approves only the agar dilution method ${ }^{15}$, disc diffusion is useful for screening many samples ${ }^{23}$. Compared to the water based extract, the ethanolic extract had much greater inhibitory activity against $H$. pylori but it was considerably lower compared to clarithromycin, a standard antibiotic used in combinations to kill $H$. pylori in patients. To our knowledge, this result is the first report for the effects of A. krervanh extracts on $H$. pylori. However, these extracts have shown inhibitory properties against some Gram-positive (e.g., Staphylococcus aureus) and Gram-negative (e.g., E. coli) bacteria. The mechanism of action in these bacteria is thought to be distortion of cell wall and cytoplasmic membranes by the essential oils, which result in leakage of several vital intracellular constituents ${ }^{24}$, as well as the disruption of DNA, RNA, protein, and polysaccharide synthesis, leading to cell death ${ }^{25}$.

It is well known that proinflammatory cytokines induced by LPS, such as NO, TNF- $\alpha$ and IL-6, play a key role in the acute inflammatory response ${ }^{26}$. We found that the ethanolic extract significantly inhibited IL- 6 in a dose-dependent manner, had weak inhibitory effects on NO production and only inhibited TNF- $\alpha$ at the highest dose $(100 \mu \mathrm{g} / \mathrm{ml})$. Previous work has shown that the 1,8-cineole (Eucalytol) from A. krervanh suppressed the production of proinflammatory cytokines, including NF- $\kappa \mathrm{B}$, TNF- $\alpha$, IL- $1 \beta$, and IL- $6{ }^{27}$. In addition, 1,8-cineole also reduced significant anti-inflammatory activity 
Table 1 Extraction yields (\% w/w), total phenolic, total flavonoid contents and antioxidant activity (concentration of $100 \mu \mathrm{g} / \mathrm{ml}$ and $\mathrm{IC}_{50} \mu \mathrm{g} / \mathrm{ml}$ ) of $A$. krervanh extracts!

\begin{tabular}{|c|c|c|c|c|c|c|c|}
\hline \multirow{2}{*}{$\begin{array}{l}\text { A. krervanh } \\
\text { Extract/control }\end{array}$} & \multirow{2}{*}{$\begin{array}{c}\text { Extraction } \\
(\%)\end{array}$} & \multirow{2}{*}{$\begin{array}{c}\text { Phenolic } \\
\text { (mg GAE/g) }\end{array}$} & \multirow{2}{*}{$\begin{array}{c}\text { Flavonoid } \\
\text { (mg GAE/g) }\end{array}$} & \multicolumn{2}{|c|}{ DPPH assay } & \multicolumn{2}{|c|}{ ABTS assay } \\
\hline & & & & $\%$ inhibitio & $\mathrm{IC}_{50}(\mu \mathrm{g} / \mathrm{ml})$ & $\%$ inhibition & $\mathrm{IC}_{50}(\mu \mathrm{g} / \mathrm{ml})$ \\
\hline Vater & & 31 & 3.13 & 72.04 & $51.08 \pm$ & & 127.64 \\
\hline 95\% Ethanol & 1.71 & $36.95 \pm 0.65$ & $4.87 \pm 0.50$ & $51.94 \pm 1.07$ & 95.92 & $53.24 \pm 1.04$ & .25 \\
\hline BHT & & & & $85.61 \pm 1.38$ & $16.02 \pm 0.59$ & $102.50 \pm 3.83$ & $5.05 \pm 0.69$ \\
\hline
\end{tabular}

${ }^{\dagger}$ Each reported value represents the mean \pm standard error of the mean of triplicates. ABTS $=2,2$-azino-bis-3ethylbenzothiazoline-6-sulphonic acid; BHT = butylated hydroxytoluene; DPPH = 2,2-diphényl picrylhydrazyl.

$\$ \%$ inhibition at concentration of $100 \mu \mathrm{g} / \mathrm{ml}$.

Table 2 In vitro anti- $H$. pylori activity of $A$. krervanh extracts against 6 clinical isolates and standard strain, expressed as the disc diffusion method and minimum inhibitory concentration $(\mu \mathrm{g} / \mathrm{ml})$. Clarithromycin was used as positive control!

\begin{tabular}{|c|c|c|c|c|c|c|c|c|}
\hline \multirow{2}{*}{$\begin{array}{l}\text { A. krervanh } \\
\text { Extract/control }\end{array}$} & \multicolumn{2}{|c|}{ ATCC43504 } & \multicolumn{2}{|c|}{ CS24 } & \multicolumn{2}{|c|}{9820} & \multicolumn{2}{|c|}{ SM100 } \\
\hline & $\begin{array}{c}\text { Inhibition } \\
\text { zone (mm) }\end{array}$ & $\begin{array}{c}\text { MIC } \\
(\mu \mathrm{g} / \mathrm{ml})\end{array}$ & $\begin{array}{c}\text { Inhibition } \\
\text { zone (mm) }\end{array}$ & $\begin{array}{c}\text { MIC } \\
(\mu \mathrm{g} / \mathrm{ml})\end{array}$ & $\begin{array}{c}\text { Inhibition } \\
\text { zone (mm) }\end{array}$ & $\begin{array}{c}\text { MIC } \\
(\mu \mathrm{g} / \mathrm{ml})\end{array}$ & $\begin{array}{c}\text { Inhibition } \\
\text { zone (mm) }\end{array}$ & $\begin{array}{c}\text { MIC } \\
(\mu \mathrm{g} / \mathrm{ml})\end{array}$ \\
\hline Water & 0 & 2000 & 0 & 2000 & 0 & 4000 & 0 & 4000 \\
\hline 95\% Ethanol & $12.0 \pm 0.0$ & 250 & $9.0 \pm 1.0$ & 250 & $14.0 \pm 0.0$ & 250 & $14.0 \pm 1.0$ & 250 \\
\hline Clarithromycin & $60.0 \pm 0.0$ & 0.5 & $57.3 \pm 0.5$ & 0.5 & $60.0 \pm 0.0$ & 0.5 & $62.0 \pm 0.0$ & 0.5 \\
\hline A. krervanh & \multicolumn{2}{|c|}{ CS46 } & \multicolumn{2}{|c|}{2693} & \multicolumn{2}{|c|}{2691} & & \\
\hline Extract/control & $\begin{array}{l}\text { Inhibition } \\
\text { zone (mm) }\end{array}$ & $\begin{array}{c}\text { MIC } \\
(\mu \mathrm{g} / \mathrm{ml})\end{array}$ & $\begin{array}{c}\text { Inhibition } \\
\text { zone (mm) }\end{array}$ & $\begin{array}{c}\text { MIC } \\
(\mu \mathrm{g} / \mathrm{ml})\end{array}$ & $\begin{array}{c}\text { Inhibition } \\
\text { zone }(\mathrm{mm})\end{array}$ & $\begin{array}{c}\text { MIC } \\
(\mu \mathrm{g} / \mathrm{ml})\end{array}$ & & \\
\hline Water & 0 & 2000 & 0 & 2000 & 0 & 2000 & & \\
\hline 95\% Ethanol & $15.0 \pm 0.0$ & 250 & $14.0 \pm 1.0$ & 250 & $19.3 \pm 0.5$ & 250 & & \\
\hline Clarithromycin & $51.0 \pm 0.0$ & 1 & $49.3 \pm 1.0$ & 1 & $67.0 \pm 0.0$ & 1 & & \\
\hline
\end{tabular}

${ }^{\dagger}$ Final amount of crude plant extract $=1 \mathrm{mg} /$ disc. Each experiment was repeated in triplicate.

in asthma patients by inhibition of mediator production $^{28}$. The report recently shown that 1,8 -cineol revealed a steroid-like suppression of arachidonic acid metabolism and cytokine production in vitro ${ }^{29}$.

We found that the radical scavenging activity of the water extract was less than the ethanolic extract when assessed by the $\mathrm{ABTS}^{+}$assay; the reverse was true by the DPPH assay, consistent with earlier reports. The crude water and ethyl acetate extracts showed radical scavenging effects of $60 \%$ and $30 \%$ at $2 \mathrm{mg} / \mathrm{ml}$ using DPPH method, respectively ${ }^{30}$, and Jeong et al obtained similar results ${ }^{31}$, while 1.8cineol had almost no antioxidant activity ${ }^{32}$.

The results indicated the influence of the extraction solvent on the total phenolic content. This could probably be due to their higher polarity and

Table 3 Effect of A. krervanh extracts on NO, TNF- $\alpha$ and IL-6 production by macrophage RAW 264.7 cells stimulated with $5 \mu \mathrm{g} / \mathrm{ml}$ of lipopolysaccharide. Prednisolone, paracetamol and andrographolide were used as positive control!

\begin{tabular}{lccrcrr}
\hline \multirow{2}{*}{ krervanh } & \multicolumn{2}{c}{ NO } & \multicolumn{2}{c}{ TNF- $\alpha$} & \multicolumn{2}{c}{$\mathrm{IL}-6^{-6}$} \\
\cline { 2 - 7 } Extract & $\%$ inhibition & $\mathrm{IC}_{50}(\mu \mathrm{g} / \mathrm{ml})$ & $\%$ inhibition & $\mathrm{IC}_{50}(\mu \mathrm{g} / \mathrm{ml})$ & $\%$ inhibition & $\mathrm{IC}_{50}(\mu \mathrm{g} / \mathrm{ml})$ \\
\hline Water & $10.23 \pm 3.12$ & $>100$ & $30.25 \pm 6.97$ & $>100$ & $2.65 \pm 1.65$ & $>100$ \\
95\% Ethanol & $52.12 \pm 2.54$ & $98.99 \pm 0.39$ & $1.24 \pm 0.24$ & $>100$ & $66.56 \pm 7.61$ & $18.68 \pm 2.16$ \\
Prednisolone & - & - & $95.95 \pm 0.88$ & $0.11 \pm 0.00$ & - & - \\
Paracetamol & $1.53 \pm 0.42$ & $>100$ & $0.32 \pm 0.05$ & $>10$ & $73.87 \pm 0.59$ & $32.14 \pm 2.69$ \\
Andrographolide & $99.13 \pm 0.14$ & $1.80 \pm 0.42$ & $92.85 \pm 0.89$ & $5.08 \pm 3.48$ & $96.12 \pm 0.29$ & $9.10 \pm 0.61$ \\
\hline
\end{tabular}

\footnotetext{
$\dagger$ Each value represents the mean \pm S.E.M. of triplicates.

$\$ \%$ inhibition at concentration of $100 \mu \mathrm{g} / \mathrm{ml}$.
} 
better solubility for phenolic compounds present in this plant ${ }^{33}$. Also, the data revealed the correlations of total phenolic content with antioxidant, anti$H$. pylori activity and anti-inflammatory activities. A similar finding was reported for the relative extraction time, flavonoid contents and antioxidant activity in Amomum species ${ }^{34}$.

In conclusion, our study revealed that the extracts of A. krervanh inhibited $H$. pylori and displayed promising anti-inflammatory activity against IL-6 and NO as well as antioxidant activity. Although the MICs against $H$. pylori were higher compared to clarithromycin, A. krervanh extracts could be used in the future as an adjunct treatment for treating $H$. pylori related disease, notably peptic ulceration. More preclinical work is needed before $A$. krervanh extracts can be medically examined for use in humans.

Acknowledgements: This work was supported by Faculty of Medicine, Thammasat University for providing equipment used for biological assays. We thank Dr Bob Taylor for reviewing the manuscript.

\section{REFERENCES}

1. Jung HK (2011) Rome III criteria for functional gastrointestinal disorders: Is there a need for a better definition? J Neurogastroenterol Motil 17, 211-2.

2. Ghoshal UC, Singh R, Chang FY, Hou X, Wong BC, Kachintorn U (2011) Epidemiology of uninvestigated and functional dyspepsia in Asia: Facts and fiction. $J$ Neurogastroenterol Motil 17, 235-44.

3. Kachintorn U (2011) Epidemiology, approach and management of functional dyspepsia in Thailand. $J$ Gastroenterol Hepatol 26, 32-4.

4. Andersen LP, Holck S, Janulaityte-Gunther D, Kupcinskas L, Kiudelis G, Jonaitis L, Janciauskas D, Holck P, et al (2005) Gastric inflammatory markers and interleukins in patients with functional dyspepsia, with and without Helicobacter pylori infection. FEMS Immunol Med Microbiol 44, 233-8.

5. Nair KPP (2006) The agronomy and economy of cardamom (Elettaria cardamomum M.): The 'Queen of spices'. Adv Agron 91, 179-471.

6. Tefera W, Wannakrairoj S (2004) Micropropagation of Krawan (Amomum krervanh Pierre ex Gagnep). ScienceAsia 30, 9-15.

7. Przygodzka M, Zielinska D, Ciesarova Z, Kukurova K, Zielinski H (2014) Comparison of methods for evaluation of the antioxidant capacity and phenolic compounds in common spices. Lwt Food Sci Technol 58, 321-6.

8. Kamchonwongpaisan S, Nilanonta C, Tamchompoo B, Thebtaranonth C, Thebtaranonth Y, Yuthavong Y, Kongsaeree P, Clardy J (1995) An antimalarial peroxide from Amomum krervanh Pierre. Tetrahedron Lett 36, 1821-4.

9. Feng X, Jiang ZT, Wang Y, Li R (2011) Composition comparison of essential oils extracted by hydro distillation and microwave-assisted hydrodistillation from Amomum kravanh and Amomum compactum. J Essent Oil Bear Pl 14, 354-9.

10. Diao WR, Zhang LL, Feng SS, Xu JG (2014) Chemical composition, antibacterial activity, and mechanism of action of the essential oil from Amomum kravanh. $J$ Food Prot 77, 1740-6.

11. Dewhirst FE (1980) Structure-activity relationships for inhibition of prostaglandin cyclooxygenase by phenolic compounds. Prostaglandins 20, 209-22.

12. Ogata SK, Gales AC, Kawakami E (2014) Antimicrobial susceptibility testing for Helicobacter pylori isolates from Brazilian children and adolescents: comparing agar dilution, E-test, and disk diffusion. Braz $J$ Microbiol 45, 1439-48.

13. Atapour M, et al (2009) In vitro susceptibility of the Gram-negative bacterium Helicobacter pylori to extracts of Iranian medicinal plants. Pharm Biol 47, 77-80.

14. Wong WM, et al (2005) Standard treatment for $\mathrm{He}^{-}$ licobacter pylori infection is suboptimal in non-ulcer dyspepsia compared with duodenal ulcer in Chinese. Aliment Pharmacol Ther 21, 73-81.

15. Clinical and Laboratory Standards Institute (2003) Methods for dilution antimicrobial susceptibility tests for bacteria that grow aerobically, 6th edn, CLSI document M7-A6, PA, USA.

16. Dechayont B, et al (2017) Antioxidant activities and phytochemical constituents of Antidesma thwaitesianum Mull. Arg. leaf extracts. J Integr Med 15, 310-9.

17. Saraphanchotiwitthaya A, Sripalakit P (2015) Antiinflammatory activity of a Vernonia cinerea methanolic extract in vitro. ScienceAsia 41, 392-9.

18. Jin SE, Kim OS, Yoo SR, Seo CS, Kim Y, Shin HK, Jeong SJ (2016) Anti-inflammatory effect and action mechanisms of traditional herbal formula GamisoyoSan in raw 264.7 macrophages. BMC Complement Altern Med 16, 219.

19. Yamazaki K, Hashimoto A, Kokusenya Y, Miyamoto T, Sato T (1994) Electrochemical method for estimating the antioxidative effect of methanol extracts of crude drugs. Chem Pharm Bull 42, 1663-5.

20. Dechayont B, Hansakul P, Itharat A (2012) Comparison of antimicrobial, antioxidant activities and total phenolic content of Antidesma thwaitesianum fruit extracts by different methods. J Med Assoc Thai 95S1, 147-53.

21. Re R, et al (1999) Antioxidant activity applying an improved ABTS radical cation decolorization assay. Free Radic Biol Med 26, 1231-7.

22. Hansakul P, Dechayont B, Phuaklee P, Prajuabjinda O, Juckmeta T, Itharat A (2015) Cytotoxic and antioxi- 
dant activities of Antidesma thwaitesianum Müll Arg (Euphorbiaceae) fruit and fruit waste extracts. Trop J Pharm Res 14, 627-34.

23. Guzeldag G, Kadioglu L, Mercimek A, Matyar F (2014) Preliminary examination of herbal extracts on the inhibition of Helicobacter pylori. Afr $J$ Tradit Complement Altern Med 11, 93-6.

24. Rhayour K, Bouchikhi T, Tantaoui-Elaraki A, Sendide K, Remmal A (2003) The mechanism of bactericidal action of oregano and clove essential oils and of their phenolic major components on Escherichia coli and Bacillus subtilis. J Essent Oil Res 15, 356-62.

25. Wu VC, Qiu X, de los Reyes BG, Lin CS, Pan Y (2009) Application of cranberry concentrate (Vaccinium macrocarpon) to control Escherichia coli O157:H7 in ground beef and its antimicrobial mechanism related to the downregulated slp, hdeA and cfa. Food Microbiol 26, 32-8.

26. Zhang JM, An J (2007) Cytokines, inflammation, and pain. Int Anesthesiol Clin 45, 27-37.

27. Lima PR, et al (2013) 1,8-cineole (eucalyptol) ameliorates cerulein-induced acute pancreatitis via modulation of cytokines, oxidative stress and NF-kappaB activity in mice. Life Sci 92, 1195-201.

28. Juergens UR, et al (2003) Anti-inflammatory activity of 1.8-cineol (eucalyptol) in bronchial asthma: a double-blind placebo-controlled trial. Respir Med 97,
250-6.

29. Juergens UR, Stober M, Vetter H (1998) Inhibition of cytokine production and arachidonic acid metabolism by eucalyptol (1.8-cineol) in human blood monocytes in vitro. Eur J Med Res 3, 508-10.

30. Asimi OA, Sahu NP, Pal AK (2013) Antioxidant capacity of crude water and ethyl acetate extracts of some Indian spices and their antimicrobial activity against Vibrio vulnificus and Micrococcus luteus. J Med Plants Res 7, 1907-5.

31. Jeong SC, Tulasi R, Koyyalamudi SR (2016) Antioxidant capacities of hot water extracts and endopolysaccharides of selected Chinese medicinal fruits. Cancers 8, 33.

32. Zengin H, Baysal AH (2014) Antibacterial and antioxidant activity of essential oil terpenes against pathogenic and spoilage-forming bacteria and cell structure-activity relationships evaluated by SEM microscopy. Molecules 19, 17773-98.

33. Nakamuraa M, Ra J-H, Jee Y, Kim J-S (2017) Impact of different partitioned solvents on chemical composition and bioavailability of Sasa quelpaertensis Nakai leaf extract. $J$ Food Drug Anal 25, 316-26.

34. Butsat S, Siriamornpun S (2016) Effect of solvent types and extraction times on phenolic and flavonoid contents and antioxidant activity in leaf extracts of Amomum chinense C. Int Food Res J 23, 180-7. 